\title{
Novel Monoclonal Antibody Recognition of Oxidative DNA Damage Adduct, Deoxycytidine-Glyoxal
}

\author{
Nalini Mistry, Ian Podmore, Marcus Cooke, Paul Butler, Helen Griffiths, \\ Karl Herbert, and Joseph Lunec
}

Oxidative Stress Group, Department of Clinical Biochemistry (NM, MC, JL), Department of Pathology (KH), Leicester Royal Infirmary, University Hospitals of Leicester National Heath Service Trust, Leicester, and Department of Chemistry (IP), School of Sciences, University of Salford, Salford, and Cancer Research Group (PB), DeMontfort University, Leicester, and Pharmaceutical Sciences Research Institute (HG), Aston University, Aston Triangle, Birmingham, United Kingdom

SUMMARY: Glyoxal, a reactive aldehyde, is a decomposition product of lipid hydroperoxides, oxidative deoxyribose breakdown, or autoxidation of sugars, such as glucose. It readily forms DNA adducts, generating potential carcinogens such as glyoxalated deoxycytidine (gdC). A major drawback in assessing gdC formation in cellular DNA has been methodologic sensitivity. We have developed an mAb that specifically recognizes gdC. Balb/c mice were immunized with DNA, oxidatively modified by UVC/hydrogen peroxide in the presence of endogenous metal ions. Although UVC is not normally considered an oxidizing agent, a UVC/hydrogen peroxide combination may lead to glyoxalated bases arising from hydroxyl radical damage to deoxyribose. This damaging system was used to induce numerous oxidative lesions including glyoxal DNA modifications, from which resulted a number of clones. Clone F3/9/H2/G5 showed increased reactivity toward glyoxal-modified DNA greater than that of the immunizing antigen. ELISA unequivocally showed Ab recognition toward gdC, which was confirmed by gas chromatography-mass spectrometry of the derivatized adduct after formic acid hydrolysis to the modified base. Binding of Ab F3/9 with glyoxalated and untreated oligomers containing deoxycytidine, deoxyguanosine, thymidine, and deoxyadenosine assessed by ELISA produced significant recognition $(p>0.0001)$ of glyoxal-modified deoxycytidine greater than that of untreated oligomer. Additionally, inhibition ELISA studies using the glyoxalated and native deoxycytidine oligomer showed increased recognition for $\mathrm{gdC}$ with more than a 5-fold difference in $\mathrm{IC}_{50}$ values. DNA modified with increasing levels of iron (II)/EDTA produced a dose-dependent increase in Ab F3/9 binding. This was reduced in the presence of catalase or aminoguanidine. We have validated the potential of $\mathrm{gdC}$ as a marker of oxidative DNA damage and showed negligible cross-reactivity with 8-oxo-2'-deoxyguanosine or malondialdehyde-modified DNA as well as its utility in immunocytochemistry. Formation of the gdC adduct may involve intermediate structures; however, our results strongly suggest Ab F3/9 has major specificity for the predominant product, 5-hydroxyacetyl-dC. (Lab Invest 2003, 83:241-250).

\begin{abstract}
$T$ ipid peroxidation is increasingly becoming a focus Lof attention as a generator of aldehyde-DNA adducts, with a potential role in carcinogenesis (Marnett, 2000). This is particularly the case for reactive aldehydes, such as malondialdehyde, 4-hydroxynonenal, and glyoxal. Recent advances in analytical and immunochemical techniques have also increased the potential for detecting physiologically relevant levels of adducts between DNA, protein, and reactive aldehydes (Sevilla et al, 1997; Tanaka et al, 2001; Uchida et al, 1993; Vay et al, 2001). Experimental reports have described elevated adduct levels after oxidative insult in vitro (Cordeiro and Freire, 1996; Everett et al, 2001;
\end{abstract}

\section{DOI: 10.1097/01.LAB.0000053915.88556.ED}

Received September 26, 2002.

This work was supported by the Ministry of Agriculture Fisheries and Food (ANO425).

Address reprint requests to: Dr. N. Mistry, Oxidative Stress Group, Department of Clinical Biochemistry, Robert Kilpatrick Clinical Sciences Building, PO Box 65, Leicester Royal Infirmary, University Hospitals of Leicester NHS Trust, Leicester, LE2 7LX, UK.
Mistry et al, 1999; Odani et al, 1998; Ruef et al, 2001). Evidence for the presence of such adducts has also been presented in conditions in which oxidative stress is strongly implicated in the etiology, such as diabetes (AR Al-Turkistani, PhD thesis, Department of Clinical Biochemistry, Leicester University, Leicester, United Kingdom, 1999) and autoimmunity (Amara et al, 1995; Grune et al, 1997; Waszczkowska et al, 1997).

Glyoxal, a dialdehyde product of the autoxidation of lipids (Loidl-Stahlhofen and Spiteller, 1994), ascorbic acid (Mlakar et al, 1996), and glucose (Kasai and Nishimura, 1986; Thornalley, 1985; Wells-Knecht et al, 1995), is also generated from the oxidative degradation of deoxyribose (Awada and Dedon, 2001; Mistry et al, 1999; Murata-Kamiya et al, 1995). It is suggested that glyoxal, generated from hydroxyl radical attack at C-4 or C-3 of deoxyribose, would readily modify nearby DNA bases. Glyoxal DNA adducts are potential endogenous and environmental mutagens. Furthermore, diets rich in precursors of reactive aldehydes, such as the polyunsaturated fatty acids identified in many food- 
stuffs, have the potential to generate glyoxalated DNA adducts.

Glyoxalated deoxycytidine (gdC) is a relevant marker of oxidative and peroxidative DNA damage. However, the lack of analytical sensitivity for the detection of $\mathrm{gdC}$ associated with current methods (Kasai et al, 1998) has limited the measurement of these adducts in biologic material. Analysis using gas chromatography-mass spectrometry (GC-MS) can potentially increase sensitivity of gdC detection; however, this procedure may not be amenable to largescale sample throughput. Antibodies that recognize oxidative DNA lesions have repeatedly been shown to be applicable for analysis of small amounts of biologic material, with high sample throughput (Sevilla et al, 1997; Toyokuni et al, 1997).

Various antibodies, both polyclonal and monoclonal, to lipid peroxidation-derived adducts have been described: with protein and DNA, such as malondialdehyde (Sevilla et al, 1997); 2-propenal (ie, acrolein) (Foiles et al, 1989; Satoh et al, 1999); 2-butenal (ie, crotonaldehyde) (Ichihashi et al, 2001); and glyoxal (Mistry et al, 1999). We herein report on the production of a novel mAb that has specificity for a deoxycytidineglyoxal adduct, and we highlight its potential application for the analysis of $\mathrm{gdC}$ in biologic samples using ELISA-based methodology. A novel strategy was used to immunize with a complex mixture of oxidatively modified DNA rather than a purified immunogen.

\section{Results}

\section{Antigenicity of Oxygen Free Radical-Modified DNA}

Initial screening of crude F3/9 supernatant, from a mixed cell population before cloning, demonstrated glyoxal-modified DNA as an effective antigen in comparison to native DNA. Only minimal recognition of the immunizing antigen, UVC/hydrogen peroxidemodified DNA (UVC/ $\mathrm{H}_{2} \mathrm{O}_{2}-\mathrm{DNA}$ ), was observed (Fig. 1). Unless stated otherwise, all further studies were performed with mAb-containing cell culture superna-

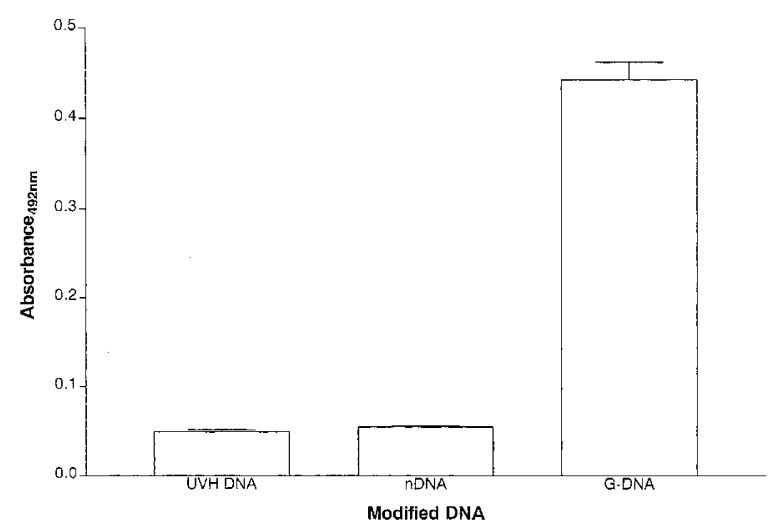

Figure 1.

Binding of $A b F 3 / 9$ (crude supernatant from mixed cell population before cloning) to glyoxal-modified, $\mathrm{UVC} / \mathrm{H}_{2} \mathrm{O}_{2}$-modified, and native DNA determined by direct ELISA. Values represent the mean (SD) of six determinations per concentration. tant after cloning. Additional studies with DNA incubated with equimolar concentrations of $\mathrm{Fe}^{2+} / E D T A$ (0-5 mM), a procedure shown previously to generate reactive oxygen species-derived modifications, as well as glyoxalated DNA bases (Mistry et al, 1999; Murata-Kamiya et al, 1995), produced a dosedependent increase in Ab binding (Fig. 2). The presence of catalase $(500 \mathrm{U} / \mathrm{ml})$, an acknowledged inhibitor of Fenton chemistry through degradation of $\mathrm{H}_{2} \mathrm{O}_{2}$, reduced the modification of DNA by the $\mathrm{Fe}^{2+} /$ EDTA system as recognized by Ab F3/9 (Fig. 2), suggesting $\mathrm{Ab}$ recognition of oxygen free radical-modified DNA. Addition of aminoguanidine (1.25 mM), which effectively binds glyoxal, to the reaction mixture also reduced Ab F3/9 binding, strongly suggesting Ab F3/9 recognizes glyoxalated DNA bases formed via Fenton chemistry. In addition, incubation of DNA with increasing concentrations of ascorbate $(0-0.625 \mathrm{~mm})$ produced a dose-dependent increase in Ab F3/9 binding (Fig. 3). It has been demonstrated previously that this reaction system readily induces glyoxalation of DNA (Mistry et al, 1999), where glyoxal is generated as a product of oxidative ascorbate degradation (Mlakar et al, 1996). The dose-dependent binding observed between ascorbate-modified DNA and Ab F3/9 was significantly reduced in the presence of catalase (500
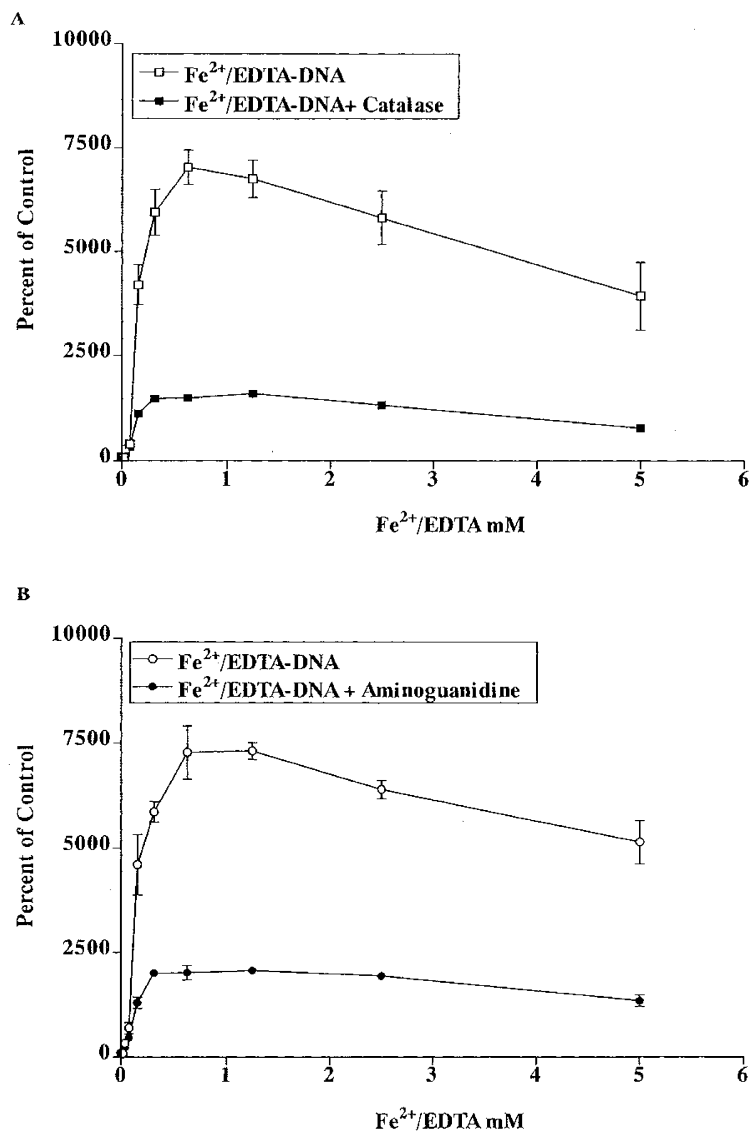

Figure 2.

Binding of $A b \mathrm{~F} 3 / 9$ (neat supernatant) to DNA incubated with (A) $\mathrm{Fe}^{2+} /$ EDTA (0-5 mm) in the presence and absence of catalase $500 \mathrm{U} / \mathrm{ml}$ or (B) aminoguanidine $1.25 \mathrm{~mm}$ determined by direct ELISA. Values represent the mean (SD) of three determinations per concentration. 


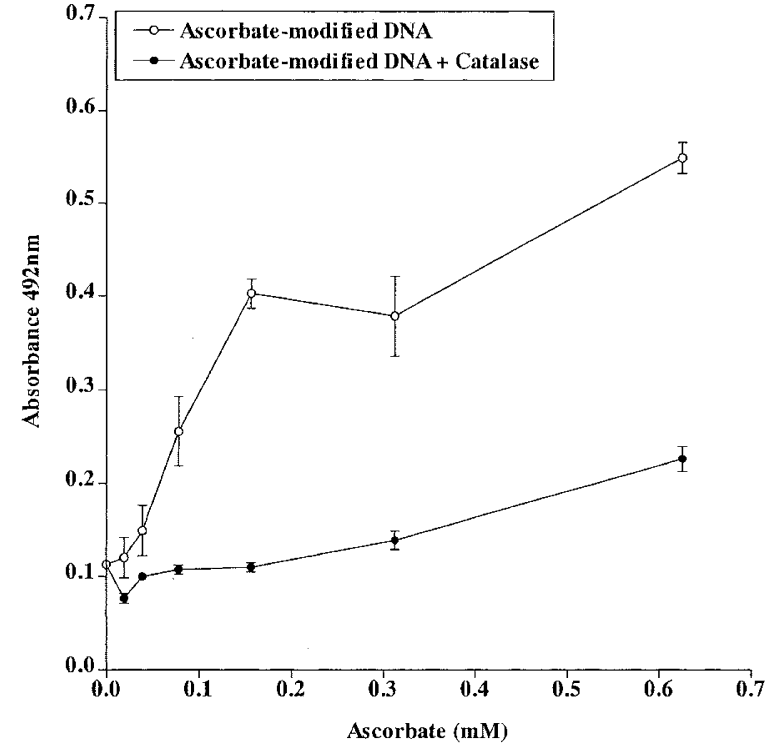

Figure 3.

Direct ELISA binding of Ab F3/9 (neat supernatant) to DNA modified with increasing levels of ascorbate $(0-2.5 \mathrm{~mm})$ in the presence and absence of catalase $(500 \mathrm{U} / \mathrm{ml})$. Values represent the mean (SD) of three determinations per concentration.

$\mathrm{U} / \mathrm{ml}$ ) (Fig. 3), providing further evidence that the gdC formation also may be mediated through hydrogen peroxide production. Standard isotyping analysis (as described in "Materials and Methods") revealed F3/9 to be of the IgM class (data not shown).

\section{Recognition of gdC Adduct Using Direct ELISA}

The specificity of Ab F3/9 for glyoxalated DNA was further investigated by direct ELISA. Oligomers (20 mer) containing exclusively deoxycytidine, deoxyadenosine, thymidine, or deoxyguanosine were each modified with glyoxal. ELISA plates were coated with these oligomers $(2.5 \mu \mathrm{g} /$ well) with corresponding untreated oligomers as controls. mAb F3/9 binding (neat supernatant, after cloning) was clearly preferentially directed toward glyoxal-modified oligomer containing deoxycytidine (oligomer $\mathrm{gdC}$ ) in comparison to other modified and unmodified oligomers (Fig. 4). Experiments were also carried out using poly-L-lysine (PLL)coated plates, to maximize attachment of the shortlength oligomers (20 mer), as well as uncoated plates for control. Both experiments showed significant increases with oligomer gdC above that of native oligomer, 11-fold with PLL plates (Fig. 4) and 79-fold with uncoated plates (Fig. 4).

\section{Recognition of gdC Adduct in Competitive ELISA}

For competitive ELISA, glyoxal-modified DNA was used as the solid-phase antigen and IgM-purified $\mathrm{Ab}$ F3/9 diluted to 1:500. Hydrogen peroxide/ascorbatemodified DNA (HASH-DNA) and glyoxal-modified double-stranded DNA effectively inhibited Ab F3/9 binding, resulting in $\mathrm{IC}_{50}$ values of 22.7 and 83.5 $\mu \mathrm{g} / \mathrm{ml}$, respectively (Table 1 ). No detectable inhibition

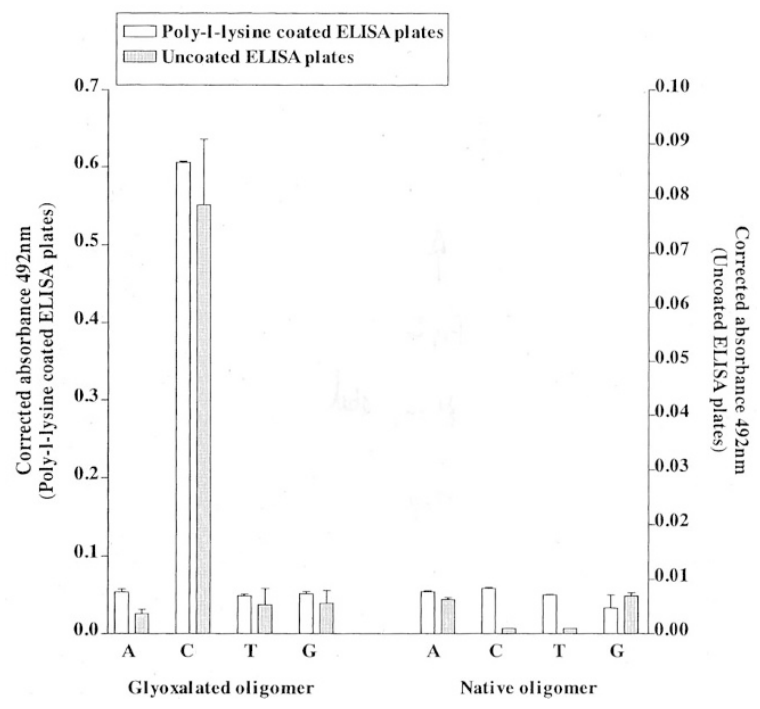

Figure 4.

Direct ELISA binding of Ab F3/9 (neat supernatant) to oligomers (20 mer) of thymidine, deoxyguanosine, deoxycytidine, and deoxyadenosine modified with glyoxal in comparison to untreated oligomer using poly-L-lysine-coated plates and uncoated plates. Values represent the mean (SD) of six determinations per concentration.

was observed with native DNA or methylene blue/ white light-modified DNA (MB-DNA), a damaging system that predominantly generates 8-oxo-2'deoxyguanosine (8-oxodG) lesions (Table 1). Inhibition analysis using oligomer $\mathrm{gdC}$ and untreated oligomer containing deoxycytidine provided further evidence for $\mathrm{Ab}$ F3/9 recognition of gdC adduct specifically $\left(\mathrm{IC}_{50}\right.$ values were 43.5 and $226.1 \mu \mathrm{g} / \mathrm{ml}$, respectively) (Table 1). Malondialdehyde has also been described to be a product of oxidative deoxyribose breakdown (Cheeseman et al, 1988). To investigate the potential cross-reactivity of malondialdehyde-modified DNA (MDA-DNA) with Ab F3/9, a competitive ELISA using glyoxal-modified DNA was used as the solid-phase antigen and neat F3/9 supernatant (Table 2). Inhibition analysis produced minimal recognition of MDA-DNA when compared with glyoxal-modified DNA ( $\mathrm{IC}_{50}$ values were 39.6 and $0.97 \mu \mathrm{g} / \mathrm{ml}$, respectively). In addi-

Table 1. Inhibition ELISA Using Antibody F3/9 Against Oxidatively modified DNA

\begin{tabular}{cc}
\hline Competing Antigen & $\begin{array}{c}\text { Competitor Inhibition } \\
I_{50} \text { Values }(\mu \mathrm{g} / \mathrm{ml})\end{array}$ \\
\hline HASH-DNA & 22.7 \\
Glyoxal DNA & 83.5 \\
MB-DNA & $>500$ \\
Native DNA & $>937$ \\
Oligomer gdC & 43.5 \\
Oligomer dC & 226.1 \\
\hline
\end{tabular}

Inhibition ELISA using IgM-purified $A b$ F3/9 at 1:500 against glyoxalmodified DNA with HASH-DNA $\left(\mathrm{IC}_{50}=22.7 \mu \mathrm{g} / \mathrm{ml}\right)$, glyoxal-modified DNA $\left(\mathrm{IC}_{50}=83.5 \mu \mathrm{g} / \mathrm{ml}\right)$, glyoxalated $\left(\mathrm{IC}_{50}=43.5 \mu \mathrm{g} / \mathrm{ml}\right)$, and native oligomer $\left(\mathrm{IC}_{50}=226.1 \mu \mathrm{g} / \mathrm{ml}\right)$ containing deoxycytidine. No inhibition was detected for native or MB-DNA up to concentrations of 500 and $937 \mu \mathrm{g} / \mathrm{ml}$, respectively. Values represent the mean of duplicate determinations. 
Table 2. Inhibition ELISA Using Antibody F3/9 Against Glyoxal- and MDA-Modified DNA

\begin{tabular}{cc}
\hline & Competitor Inhibition \\
Competing Antigen & $\mathrm{IC}_{50}$ Values $(\mu \mathrm{g} / \mathrm{ml})$ \\
\hline Native DNA & 118.9 \\
Glyoxal DNA & 0.97 \\
MDA-DNA & 39.6 \\
\hline
\end{tabular}

Inhibition ELISA using Ab F3/9 (neat supernatant) against glyoxal-modified DNA with glyoxal-modified DNA $\left(\mathrm{IC}_{50}=0.97 \mu \mathrm{g} / \mathrm{ml}\right)$, MDA-modified DNA $\left(\mathrm{IC}_{50}=39.6 \mu \mathrm{g} / \mathrm{ml}\right)$, and native DNA $\left(\mathrm{IC}_{50}=118.9 \mu \mathrm{g} / \mathrm{ml}\right)$. Values represent the mean of duplicate determinations.

tion $\mathrm{Ab} \mathrm{F} 3 / 9$ recognition of MDA-DNA was comparable to that of native DNA $\left(\mathrm{IC}_{50}\right.$ value $\left.=118.9 \mu \mathrm{g} / \mathrm{ml}\right)$ suggesting a strong specificity for glyoxal in comparison to MDA-DNA modifications.

\section{Detection of gdC Using GC-MS}

For the purpose of GC-MS analysis, oligomer gdC was hydrolyzed using formic acid according to the optimized method of Dizdaroglu (1994). Under the GC-MS condi- tions used, a major peak at 8.4 minutes was observed in the total ion chromatogram. Figure $5 \mathrm{~A}$ shows the $\mathrm{El}-$ mass spectrum of this peak and is believed to correspond to a trimethylsilyl derivative of 5-hydroxyacetylcytosine (Kasai et al, 1998; structure shown in Figure 5B). It consists of the molecular ion $\left(\mathrm{M}^{+}\right)$at $\mathrm{m} / \mathrm{z} 385$, along with ions at $\mathrm{m} / \mathrm{z} 370$ (loss of methyl radical from $\mathrm{M}^{+\cdot}, \mathrm{M}-15$ ) and $\mathrm{m} / \mathrm{z} 296$ (loss of $\mathrm{OSiMe}_{3}, \mathrm{M}-89$ ). Another ion observed in the mass spectrum is that at $\mathrm{m} / \mathrm{z} 356$ (M-29), which is thought to derive from the loss of $\mathrm{HCO}$ from the molecular ion. There are also other peaks in the mass spectrum that may account for possible intermediate structures leading to the predominant $\mathrm{gC}$ adduct, 5-hydroxyacetylcytosine.

\section{Immunocytochemical Analysis of gdC Adducts Using Ab F3/9}

Treatment of RHT-t25 cells with $0.4 \%$ glyoxal produced intense fluorescent staining, as a consequence of incubation with Ab F3/9 (neat supernatant) and was strictly localized to the nucleus (Fig. 6A). In contrast, negligible staining was seen in the untreated cells (Fig. $6 \mathrm{C})$. This demonstrates applicability of the mAb to the

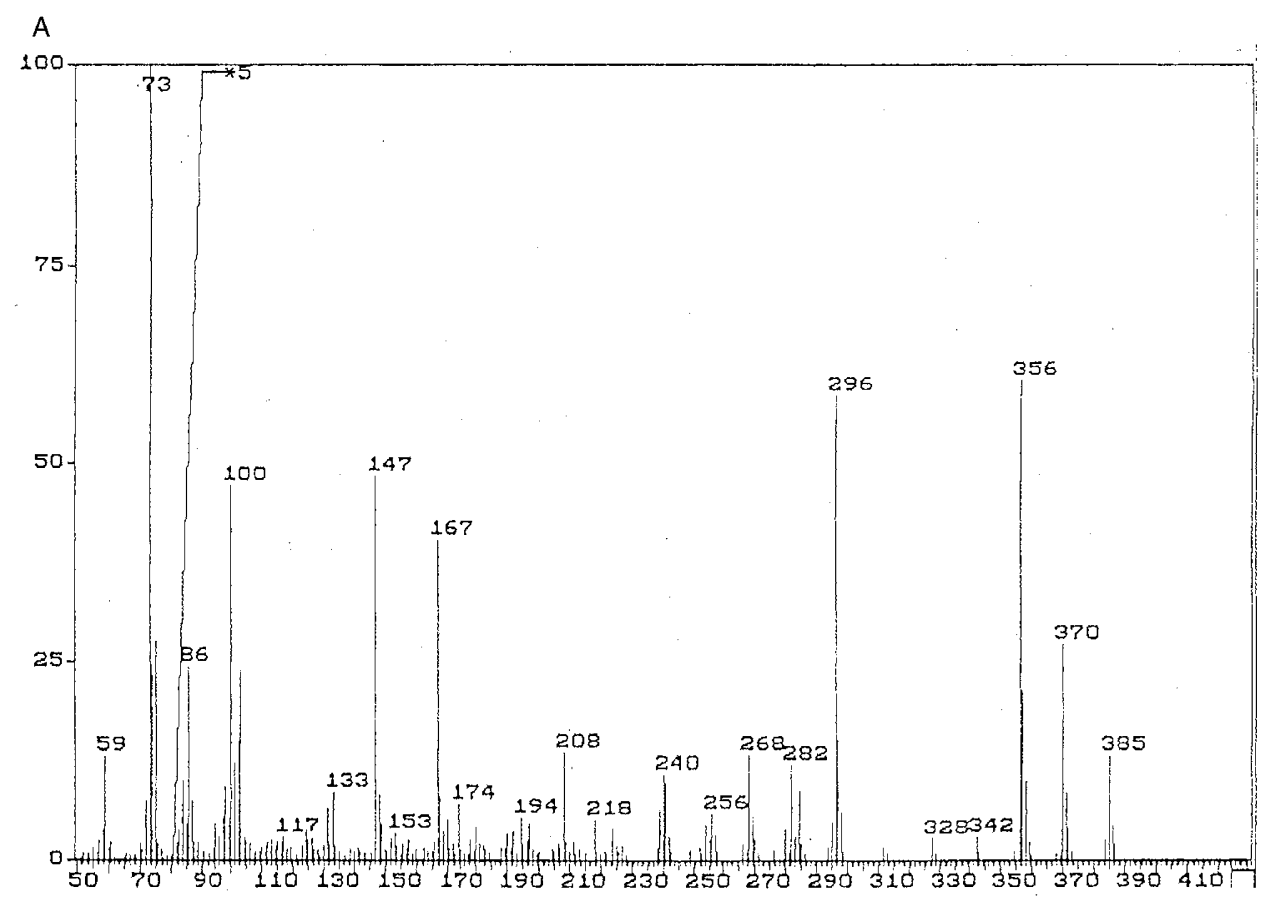

B

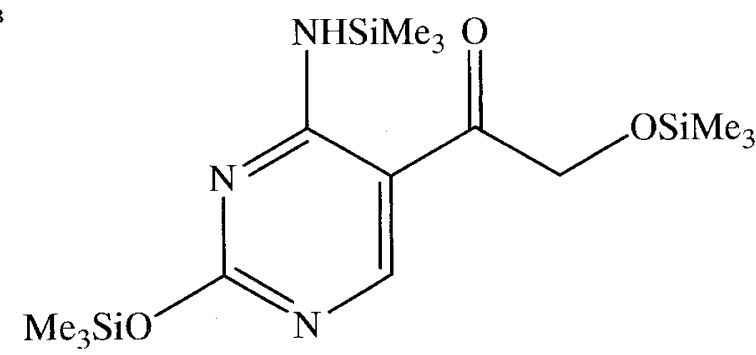

Figure 5.

Analysis of glyoxalated deoxycytidine ( $\mathrm{gdC}$ ) showing $(\mathrm{A})$ gas chromatography-mass spectrometry mass spectrum of formic acid hydrolyzed oligomer gdC and (B) structure of trimethylsilylated 5-hydroxyacetyl-C (Kasai et al, 1998). 

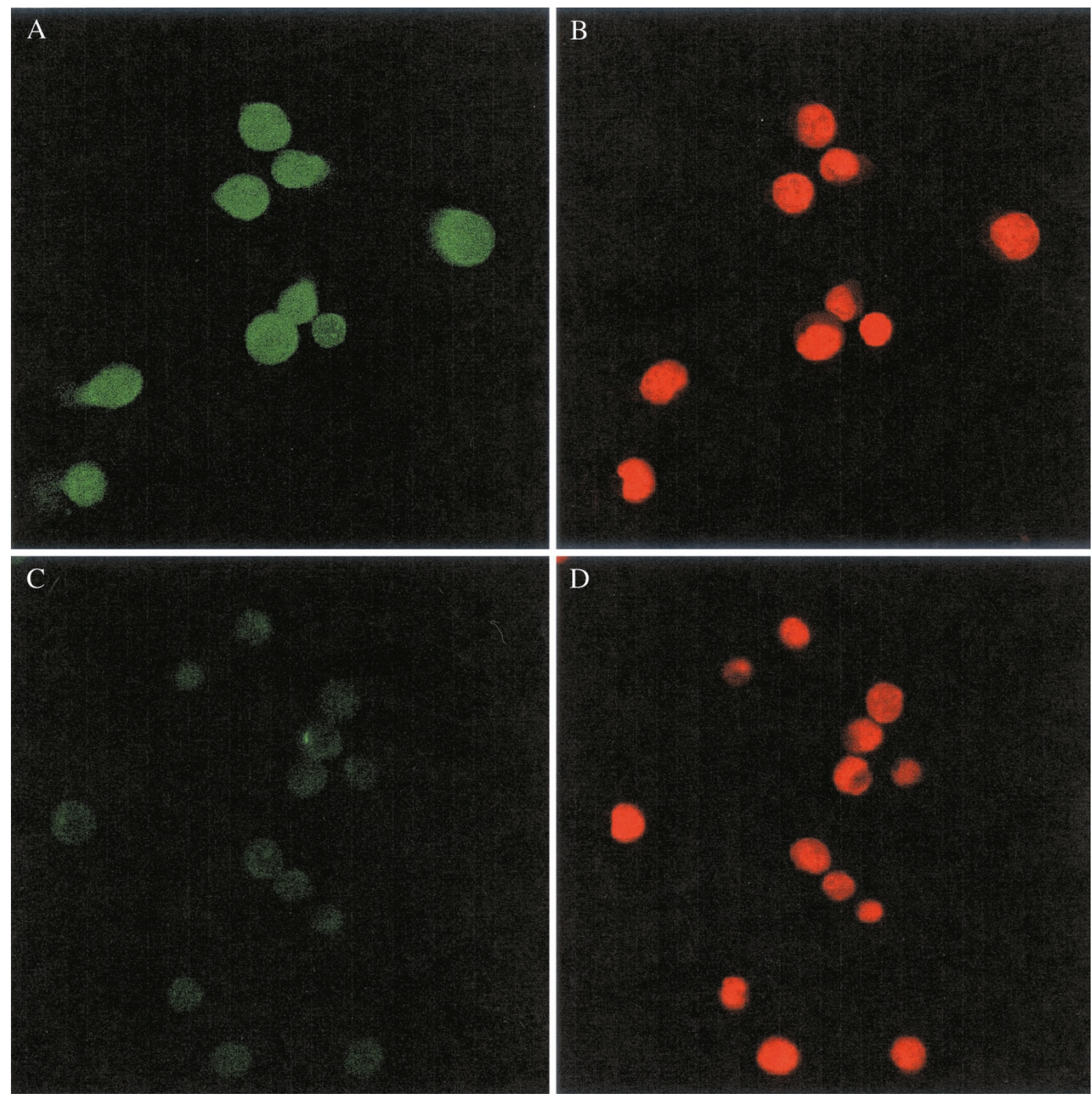

\section{Figure 6.}

Immunocytochemical analysis of Ab F3/9 staining in (A) glyoxal-treated (0.4\%) and (C) untreated RHT-t25 cells. Ab F3/9 binding (neat supernatant) was visualized using an anti-mouse FITC-labeled secondary Ab (1:50; green fluorescence). Propidium iodide (red fluorescence) was used as a nuclear counterstain in both the (B) treated and (D) untreated cells. Analyses were performed using a Leica TCS4D true confocal scanning microscope.

in situ detection of $\mathrm{gdC}$ in cells. Ab F3/9 binding was visualized using an FITC-labeled secondary Ab. Glyoxal-treated and untreated cells were counterstained with propidium iodide to identify the nuclear regions (Fig. 6, B and D).

\section{Discussion}

Glyoxal is a dicarbonyl formed approximately 17 times in excess of 8-oxodG after treatment of DNA with an $\mathrm{Fe}^{2+} /$ EDTA-damaging system (Murata-Kamiya et al, 1995). The cytotoxicity and mutagenicity of glyoxal in mammalian cells (Klamerth, 1968; Murata-Kamiya et al, 1997, 1998) have generally been related to glyox- alated guanine residues in DNA (Nakaya et al, 1968; Shapiro and Hachmann, 1966), partly because the product is easily identifiable by its ultraviolet spectrum (Murata-Kamiya et al, 1995). However, the gdC adduct has received less attention in comparison, mainly because of sensitivity problems associated with analysis by HPLC with UV detection (Kasai et al, 1998) and spectrophotometric analysis (Nakaya et al, 1968). This detection problem can potentially be overcome using GC-MS analysis, however derivatization procedures may induce artifactual DNA damage and involve lengthy sample preparation (Ravanat et al, 1995). Preparation time can therefore be minimized using immunochemical techniques that can also simplify 
sample preparation. We have developed a novel mAb (F3/9) against the gdC adduct using an immunization protocol devised to produce antibodies against both oxidative DNA base damage (Dizdaroglu and Bertgold, 1986; McBride et al, 1991) and those adducts arising from the oxidative degradation of the deoxyribose moiety and lipid peroxide-DNA interactions (Loidl-Stahlhofen and Spiteller, 1994; Mistry et al, 1999; Murata-Kamiya et al, 1995). It was evident from initial screenings by direct ELISA that monoclonal F3/9, from lgM-secreting clone F3/9/G2/H5, showed increased binding toward glyoxalated DNA greater than that of native DNA. The immunogen $\left(\mathrm{UVC} / \mathrm{H}_{2} \mathrm{O}_{2}-\right.$ DNA) did not show reactivity to the degree observed for glyoxalated DNA or oxidatively-modified DNA such as HASH-DNA and $\mathrm{Fe}^{2+} /$ EDTA-modified DNA using clone $F 3 / 9 / G 2 / H 5$. It would seem that $F 3 / 9$ binding reflects the $\mathrm{gdC}$ content induced in DNA by different damaging systems. Supporting evidence that glyoxal is induced by hydrogen peroxide was demonstrated by decreased Ab binding to DNA exposed to ascorbate in the presence of endogenous metal ions, after incubation with catalase. This was further evidence supporting glyoxal production and adduct formation to be a consequence of oxidative processes.

Various groups have reported on the formation of lipid peroxidation end products such as glyoxal via oxygen free radical-generating systems involving Fenton and Haber-Weiss reactions (Kasai and Nishimura, 1986; Loidl-Stahlhofen and Spiteller, 1994; Mistry et al, 1999; Thornalley, 1985; Wells-Knecht et al, 1995). Herein, we have demonstrated increased $A b$ F3/9 binding to DNA, after exposure to an $\mathrm{Fe}^{2+} /$ EDTAdamaging system. Ab binding was significantly reduced with the inclusion of catalase in the $\mathrm{Fe}^{2+} /$ EDTA DNA modification step, providing additional confirmatory evidence for the recognition of glyoxal-modified DNA formed via hydrogen peroxide-mediated DNA damage. After the addition of aminoguanidine, which effectively binds reactive aldehydes (Lo et al, 1994), in the $\mathrm{Fe}^{2+} /$ EDTA-DNA modification step, minimal $\mathrm{Ab}$ recognition was noted compared with $\mathrm{Fe}^{2+}$ /EDTAmodified DNA alone. A similar pattern of binding was observed for DNA incubated with glyoxal in the presence and absence of aminoguanidine, strongly supporting the specificity of Ab F3/9 for glyoxalated DNA. Additionally, our competitive ELISA results, with glyoxal-modified DNA as the solid-phase antigen, showed inhibition with glyoxal and $\mathrm{HASH}$-treated DNA in contrast to native DNA up to $500 \mu \mathrm{g} / \mathrm{ml}$. In view of the fact that 8-oxodG is also generated via $\mathrm{UVC} / \mathrm{H}_{2} \mathrm{O}_{2}$ treatment of DNA, MB-DNA, which specifically induces 8-oxodG formation (Floyd et al, 1989; McBride et al, 1992), was used a putative antigen. $I_{50}$ values for MB-DNA were not measurable up to levels of 937 $\mu \mathrm{g} / \mathrm{ml}$, which strongly indicated that the reactivity observed with Ab F3/9 toward oxidatively-modified DNA is primarily a result of gdC. Furthermore, $\mathrm{HASH}$ treatment, a hydroxyl radical-generating system, is more effective at producing gdC than simple incubation with glyoxal.
Malondialdehyde is also a product of oxidative deoxyribose degradation (Cheeseman et al, 1988), and immunochemical detection of malondialdehydemodified deoxyguanosine has been successfully developed by Sevilla et al (1997) using an mAb. Ab F3/9 showed negligible recognition of MDA-DNA adduct in sharp contrast to glyoxal-modified DNA. In fact, inhibition data with MDA-DNA was comparable to that of native DNA, such that an approximately 3-fold difference in $I_{50}$ values was obtained. This was in contrast to the 123-fold differences observed with glyoxalmodified $\left(\mathrm{IC}_{50}=0.97 \mu \mathrm{g} / \mathrm{ml}\right)$ and native DNA $\left(\mathrm{IC}_{50}=\right.$ $118.9 \mu \mathrm{g} / \mathrm{ml})$. In addition, the $\mathrm{IC}_{50}$ values for MDADNA were almost 40 -fold higher with respect to glyoxal-modified DNA, strongly suggesting negligible reactivity toward the MDA-DNA adduct, including malondialdehyde-modified deoxycytidine.

Further studies to investigate the nature of the antigen recognized by $A b \quad F 3 / 9$ used a series of oligomers containing either deoxycytidine, deoxyguanosine, thymidine, or deoxyadenosine. Using this approach we were able to unequivocally assign reactivity of Ab F3/9 against gdC. Given that the oligomer was a short sequence of 20 mer, ELISA plates were coated with PLL to increase solid-phase binding. However the outcome, irrespective of whether ELISA plates were PLL coated or left untreated, was significant F3/9 recognition of $\mathrm{gdC}$ greater than that of untreated oligomers. Also, the competitive ability of oligomer gdC was almost 5-fold greater than untreated oligomer when glyoxal-modified DNA was used as the solid-phase antigen. Additionally, we have presented GC-MS evidence to show that the oligomer gdC was highly modified. The molecular ion produced corresponds to the product 5-hydroxyacetyl-dC, in agreement with structural studies performed by Kasai et al (1998). Our results suggest that the structure for $\mathrm{gdC}$ is most likely 5-hydroxyacetyl-dC and that this structure is the epitope recognized by $\mathrm{Ab} F 3 / 9$ in both ELISA and immunocytochemical studies.

\section{Materials and Methods}

Glyoxal, 40\% w/v solution in water, was obtained from Sigma-Aldrich Company Ltd. (Gillingham, Dorset, United Kingdom). Cytosine (4-amino-2-hydroxypyrimidine), $30 \%$ hydrogen peroxide, ascorbic acid, O-phenylenediamine tablets (10 mg), Sigma ImmunoType mouse monoclonal isotyping kit, and peroxidase-labeled mouse immunoglobulin $\mathrm{IgM}-\mu$ chain were purchased from Sigma Chemical Company (Dorset, United Kingdom). Acetonitrile was purchased from Perbio Science (United Kingdom). Calf thymus DNA was purchased from BDH Laboratory Supplies (Poole, United Kingdom). Nunc Immuno Maxisorp 96-well ELISA plates were purchased from Life Technologies (Paisley, Scotland), and dried skimmed milk was from Tesco Stores Ltd. (United Kingdom). N,O-bis(trimethylsilyl)trifluoroacetamide and silylation grade acetonitrile were from Pierce and Warner (Chester, Cheshire, United Kingdom). All remaining chemicals were of the highest purity available (Sigma). Water was filtered through $0.22-\mu \mathrm{m}$ filter. 


\section{Preparation of HASH-DNA}

Hydrogen peroxide and ascorbate in the presence of endogenous metal ions were used for site-specific hydroxyl radical attack on DNA (Cooke et al, 1997; Mistry et al, 1999). A solution of calf thymus DNA (0.5 $\mathrm{mg} / \mathrm{ml}$, final concentration in deionized water) was incubated with $200 \mu \mathrm{M} \mathrm{H}_{2} \mathrm{O}_{2}$ and $10 \mathrm{~mm}$ ascorbate for 1 hour at $37^{\circ} \mathrm{C}$.

\section{Preparation of $\mathrm{UVC} / \mathrm{H}_{2} \mathrm{O}_{2}-\mathrm{DNA}$}

An aqueous solution ( $1 \mathrm{mg} / \mathrm{ml}$ ) of calf thymus DNA was irradiated under UVC light $(254 \mathrm{~nm})$, positioned 6 $\mathrm{cm}$ from the source, for 30 minutes at room temperature in the presence of hydrogen peroxide (15.1 mm) (Ara and Ali, 1993; Cooke et al, 1997). Excess hydrogen peroxide was then removed by dialysis against $0.01 \mathrm{~m}$ PBS, $\mathrm{pH} 7.4$, overnight at $4^{\circ} \mathrm{C}$.

\section{Preparation of Glyoxal-Modified DNA}

DNA was prepared with a final concentration of 1 $\mathrm{mg} / \mathrm{ml}$ in Milli-Q water. An equal volume of $1 \mathrm{M}$ glyoxal was incubated with the DNA solution for 1 hour at $37^{\circ} \mathrm{C}$. Glyoxal-DNA was subsequently dialyzed overnight against PBS.

\section{Preparation of MB-DNA}

Methylene blue in the presence of white light specifically oxidizes deoxyguanosine residues in DNA to yield 8-oxodeoxyguanosine adducts (McBride et al, 1992). In accordance with the method of Cooke et al (1998), a solution of calf thymus DNA $(0.5 \mathrm{mg} / \mathrm{ml}$, final concentration in deionized water) was incubated with methylene blue $(20 \mu \mathrm{g} / \mathrm{ml}$, final concentration in $0.1 \mathrm{M}$ Tris, $\mathrm{pH} \mathrm{8.5)} \mathrm{in} \mathrm{a} \mathrm{Petri} \mathrm{dish} \mathrm{on} \mathrm{ice,} \mathrm{shielded} \mathrm{from} \mathrm{a}$ white light source by $0.5 \mathrm{~cm}$ of water in an upturned Petri dish lid. Irradiation was for 3 hours, at a distance of $\sim 3 \mathrm{~cm}$, at which time solid sodium chloride was added to $1 \mathrm{M}$ and DNA precipitated with ethanol on ice. The DNA was removed by pipette and dissolved in deionized water. This procedure was repeated twice to further remove traces of methylene blue.

\section{Preparation of MDA-DNA}

DNA (1 mg/ml) was incubated with 100 mm MDA for 96 hours at $37^{\circ} \mathrm{C}$. MDA was generated in accordance with the method of Fogleman et al (1980). Briefly, 100 mм malondialdehyde bis-(dimethyl-acetal) was hydrolyzed in water under acidic conditions for 10 minutes at $37^{\circ} \mathrm{C}$. The $\mathrm{pH}$ was adjusted to 7.5 with $\mathrm{NaOH}$ and the concentration of MDA determined using spectrophotometry $\left(A_{245}\right)$. The modified DNA was then dialyzed extensively against three washes of PBS.

\section{Production of F39 mAb}

The medium consisted of RPMI 1640 (Gibco BRL, Life Technologies, Gaithersburg, Maryland) containing 20 mм complete glutamax (L-alanyl-L-glutamine) (Gibco). The $125-\mu \mathrm{m}$ mesh was obtained from Sigma. The
P3-NS0 mouse myeloma cell line was a gift from Dr. L. Durrant, CRC Academic Department, Clinical Oncology, Nottingham City Hospital. Polyethylene glycol (PEG) and FCS (FCS Hybri-max) were from Sigma. Briclone (10\%) (TCS Biologicals) was used as a supplement during fusion. Selection medium consisted of complete medium, FCS, and $1 \times$ HAT media supplement (Hybri-max; Sigma).

Female, 6-week-old Balb/c mice were immunized according to the following protocol. Reference bleeds were obtained before immunization. Damaged DNA $\left(\mathrm{UVC} / \mathrm{H}_{2} \mathrm{O}_{2}\right)$ was boiled for 10 minutes and then cooled rapidly on ice to yield single-stranded DNA before conjugation with a $1 \%$ solution of methylated BSA. This conjugate was then homogenized 1:1 with Freund's complete adjuvant. The mice $(n=3)$ were immunized with $200 \mu$ l of immunogen mix subcutaneously at multiple sites. The animals were boosted subcutaneously with $50 \mu \mathrm{g}$ of immunogen in $100 \mu \mathrm{l}$ of sterile saline 7 days later. Test bleeds were performed 7 days after boost. The animals were killed 3 days after a final intraperitoneal boost, and spleen and sera were collected when a sufficient titer of $A b$ had been obtained. The latter was assessed by ELISA. The spleen was collected into a bijou containing $5 \mathrm{ml}$ of medium. The medium used contained additives but remained free from FCS until the fusion was completed.

The preparation of an immortalized hybridoma cell line was performed as follows. The surface of a $125-\mu \mathrm{m}$ mesh was washed with a small volume of medium (as above) before the spleen was teased apart. The cells were then washed with medium. The spleen and NSO cells were mixed at a ratio of $4: 1$ and pelleted at $300 \times g$. NSO cells are an established mouse, fusion partner cell line. The medium was removed and the pellet loosened, and $800 \mu \mathrm{l}$ of PEG at $37^{\circ} \mathrm{C}$ was added slowly during a minute, while stirring continuously. Medium was then used to dilute the PEG, stirring continuously. The cells were then centrifuged and resuspended in RPMI supplemented with FCS to $15 \%$ at $2 \times 10^{6}$ spleen cells per milliliter. These cells were then plated out over $2 \times 96$-well plates at $100 \mu \mathrm{l} /$ well using RPMI $+10 \%$ FCS and incubated at $37^{\circ} \mathrm{C}$ in $5 \% \mathrm{CO}_{2}$. After 24 hours, selection medium was added, and the cultures were fed as required during the next 2 to 3 weeks with selection medium. As the wells approached $\sim 50 \%$ confluence, the supernatants were tested and the wells re-fed. Positive wells were grown in 24-well plates, before being cloned at least twice by limiting dilution.

\section{Screening of Supernatants}

The cell culture supernatants were tested by direct ELISA, with damaged DNA appropriate to the immunogen, as the solid phase antigen. Neat culture medium was used as a negative control and serum prepared from final bleed as a positive control. 


\section{Dilution Cloning}

One milliliter of cells was harvested from a positive well, and the cells were diluted to 10 cells per milliliter. The cells were then plated out onto a 96-well plate at $100 \mu \mathrm{l}$ per well (ie, 1 cell per well). A further $100 \mu \mathrm{l}$ of medium was then added to the wells and incubated at $37^{\circ} \mathrm{C}$ in $5 \% \mathrm{CO}_{2}$. At Day 6 the wells were monitored for single colonies and fed with fresh medium. Testing occurred around Days 9 to 10, with extra medium being added the day before. Three to six positives were chosen and expanded before isotyping and freezing.

\section{Isotyping Procedure}

Supernatants from the clone F3/9 were isotyped predominantly to $\mathrm{lgM}$ class antibodies. Briefly, $3 \mathrm{ml}$ of hybridoma supernatant was incubated with the isotyping strip for 30 minutes in a vial (all incubations at room temperature) followed by a single wash with PBS-T-BSA (PBS containing $0.05 \%$ Tween 20 and 1\% BSA). After 5 minutes, wash buffer was discarded and biotinylated secondary $\mathrm{Ab}$ was added at 1:50 dilution in PBS-T-BSA for 30 minutes. After incubation, the isotyping strip required another wash with PBS-T-BSA for 5 minutes. Having discarded the wash buffer, ExtrAvidinPeroxidase was added at 1:50 dilution in PBS-T-BSA and incubated for 15 minutes. After aspiration of ExtrAvidin-Peroxidase, the isotyping strip was washed once with PBS-T-BSA and then in PBS, 5 minutes for each wash. Wash buffers were discarded, and substrate solution was added. Incubation was between 1 and 10 minutes until a clear, red, insoluble signal was obtained for the positive control. The strip was then immediately placed in $0.1 \mathrm{M} \mathrm{NaOH}$ for 1 to 2 minutes and, finally, rinsed with distilled water and allowed to dry.

\section{Purification of IgM Abs}

An IgM purification kit (E-Z-SEP, cell culture IgM; Pharmacia Biotech, St. Albans, Herts, United Kingdom) was used to purify IgM antibodies from hybridoma supernatant F3/9. Before processing, supernatant was brought to room temperature before being adjusted to $\mathrm{pH} 7.3$ to 7.7. An equal volume of Separation Reagent 1 was added to supernatant and allowed to mix well for 30 minutes. After centrifugation at $2500 \mathrm{rpm}$ at 4 to $20^{\circ} \mathrm{C}$ for 60 minutes, precipitate was resuspended in Buffer Solution 2, equal to $50 \%$ of the starting supernatant volume. This solution was allowed to stand for 10 minutes at room temperature. A volume of Separation Reagent 3, equal to the volume of supernatant resuspension, was subsequently added and the procedure from centrifugation was repeated. Finally, the precipitate was resuspended in $0.1 \mathrm{M}$ Tris-base buffer, $\mathrm{pH} 9.2$, equal to $10 \%$ of the starting volume of supernatant.

\section{Oligonucleotide Purification}

Stock solutions of 20-oligomer containing deoxycytidine, deoxyguanosine, deoxyadenosine, and thymidine with dimethyl trityl groups attached were pre- pared by Protein Nucleic Acids Laboratory (MRC Centre for Mechanisms of Human Toxicity, University of Leicester, United Kingdom). Samples were obtained in ammonia, and overnight lyophilization was required followed by treatment using NENSORB columns (Dupont, United Kingdom) to remove any failed sequences. Briefly, the oligomer was reconstituted in $4 \mathrm{ml}$ of $0.1 \mathrm{M}$ triethylammonium acetate (TEAA) buffer, $\mathrm{pH}$ 7.0. The NENSORB cartridge was initially activated with $10 \mathrm{ml}$ of methanol and then pre-equilibrated with $5 \mathrm{ml}$ of TEAA buffer. The reconstituted sample was pipetted on top of the resin bed. The cartridge was subsequently washed with the following: $10 \mathrm{ml}$ of acetonitrile/0.1 M TEAA buffer (1:9 v/v), $25 \mathrm{ml}$ of $0.5 \%$ TFA buffer, and $10 \mathrm{ml}$ of 0.1 TEAA buffer. Samples were eluted with $5 \mathrm{ml}$ of $35 \%$ methanol and collected as 1-ml fractions. The OD of each sample was assessed by UV spectrophotometry at $260 \mathrm{~nm}$ (1 OD of oligomer $\mathrm{C}$ was taken as $25 \mu \mathrm{g} / \mathrm{ml}$ ).

\section{Glyoxal Treatment of Purified Oligonucleotides}

Glyoxal treatment of purified oligomers involved incubation of $4 \mathrm{ml}$ of each oligomer with $4 \mathrm{ml}$ of $1 \mathrm{M}$ glyoxal for 1 hour at $37^{\circ} \mathrm{C}$. Excess glyoxal was removed using NAP-10 columns prepacked with Sephadex G-25, DNA grade (Pharmacia Biotech). Briefly, each column was equilibrated with $15 \mathrm{ml}$ of PBS. Sample (up to 1 $\mathrm{ml}$ ) was allowed to enter the gel bed completely. Note that for samples $<1 \mathrm{ml}$, sufficient PBS was added to equal $1 \mathrm{ml}$. Finally, sample was eluted with $1.5 \mathrm{ml}$ of PBS and collected as $0.5-\mathrm{ml}$ aliquots. Assessment of glyoxal within collected fractions was performed using orthophenylenediamine derivatization as described by Murata-Kamiya et al (1995) with modifications. Briefly, $25 \mu \mathrm{l}$ from each aliquot was incubated with $25 \mu \mathrm{l}$ of $2 \%$ orthophenylenediamine solution at room temperature for 30 minutes; $500 \mu$ l of water was then added to each sample and measured at $350 \mathrm{~nm}$. A control using $1.8 \%$ glyoxal (final concentration) was used. Samples containing $<0.18 \%$ glyoxal were used for the assay. Treated samples were also lyophilized, reconstituted in water, and stored at $4^{\circ} \mathrm{C}$.

\section{ELISA}

ELISA was performed according to the method described by Herbert et al (1994), for UV-modified DNA. Briefly, double-stranded DNA $(2.5 \mu \mathrm{g} /$ well) was bound to a 96-well ELISA plate by incubation in a humidified environment at $37^{\circ} \mathrm{C}$ for 1 hour, after which the plate was washed three times with PBS. Free sites were then blocked by incubation with $200 \mu \mathrm{l} /$ well $4 \%(\mathrm{w} / \mathrm{v})$ dried skimmed milk in PBS (4\% milk/PBS) for 1 hour in a humidified environment, and the wells were then washed with PBS. Ab F3/9, $50 \mu \mathrm{l} /$ well (neat supernatant or IgM purified at $1: 500$ in $4 \%$ milk/PBS), was incubated for 1 hour as described above. After washing three times with PBS containing 0.05\% Tween 20, $50 \mu \mathrm{l} /$ well of peroxidase-labeled anti-mouse immunoglobulin IgM- $\mu$ chain (1:2000 in 4\% milk/PBS) was added and incubated as described above. A substrate 
solution, orthophenylenediamine $(0.5 \mathrm{mg} / \mathrm{ml}$ in $0.05 \mathrm{M}$ phosphate-citrate, $\mathrm{pH} 5.0$, containing $0.03 \% \mathrm{w} / \mathrm{v}$ sodium perborate) was added after a final PBS wash (50 $\mu \mathrm{l} /$ well) and incubated for 15 minutes at room temperature. The reaction was stopped using $25 \mu \mathrm{l} /$ well $2 \mathrm{M}$ $\mathrm{H}_{2} \mathrm{SO}_{4}$. The resulting absorbance was read at $492 \mathrm{~nm}$, using a plate reader (Anthos Instruments). The final data included correction for background values.

\section{Inhibition ELISA}

Inhibition ELISA was performed exactly as described for the direct binding ELISA data and included correction for background values, except $25 \mu$ l of the putative antigen (in milk/PBS) was serially diluted followed by $25 \mu \mathrm{l} /$ well of lgM-purified Ab F3/9 (1:500 in milk/PBS, final concentration). Percentage inhibitions were calculated on the basis of detection of bound $\mathrm{Ab}$ in competition wells against $\mathrm{Ab}$ binding in the noncompetition wells.

\section{GC-MS Analysis of Oligomer gdC}

Samples were formic acid hydrolyzed and derivatized to the glyoxalated cytosine base using the optimized methodology of Dizdaroglu (1994). Briefly, aliquots of $100 \mu \mathrm{g}$ of oligomer gdC or a sample of a glyoxalcytosine reaction mixture were treated with $100 \mu$ l of a mixture of N,O-bis(trimethylsilyl)trifluoroacetamide and acetonitrile $(4: 1 \mathrm{v} / \mathrm{v})$ at $120^{\circ} \mathrm{C}$ for 30 minutes under an argon atmosphere. Analyses were performed using a Perkin-Elmer Autosystem GC interfaced with a PE Q-mass 910 quadrople mass spectrometer. One microliter of the derivatization reaction mixture was injected onto the GC with the injector port in the split mode (split ratio 40:1). Separations were performed on a fused silica capillary column $(15 \mathrm{~m} \times 0.25 \mathrm{~mm}$ ID and $0.25-\mu \mathrm{m}$ stationary phase thickness; Rtx-5, Restek International). Mass spectra were recorded in the total ion scan mode in the scan range 50 to 600 amu. The injector port and transfer line were maintained at $250^{\circ} \mathrm{C}$ and $280^{\circ} \mathrm{C}$, respectively. The column temperature was increased from $120^{\circ} \mathrm{C}$ to $300^{\circ} \mathrm{C}$ at $10^{\circ} \mathrm{C} /$ minute after an initial 2 minutes at $120^{\circ} \mathrm{C}$. The carrier gas used was helium (CP grade) at a constant flow rate of $1 \mathrm{ml} /$ minute.

\section{Glyoxal Treatment of RHT-t25 Cells}

RHT-t25 cells (transformed keratinocytes; a kind gift from Prof. Irene Leigh, Department of Dermatology, London Hospital Medical College) were maintained in DMEM containing 20\% HAM-12 and 10\% FCS (Gibco BRL, Life Technologies). Keratinocytes were trypsinized and resuspended in PBS. Cells were cultured on chambered slides in growth medium until subconfluent and treated with $0.4 \%$ glyoxal in growth media for 1 hour at $37^{\circ} \mathrm{C}$. Cells were fixed in $90 \%$ ice-cold methanol for 5 minutes, washed with PBS, and incubated with Ab F3/9 (neat supernatant) for 1 hour. After a PBS wash, cells were incubated with goat antimouse FITC-labeled secondary Ab (Sigma, Poole, United Kingdom) at a dilution of 1:50 in PBS for 1 hour. All incubations were at $37^{\circ} \mathrm{C}$. The cells were finally washed in PBS and mounted in propidium iodide Vectashield (Vector Labs, Peterborough, United Kingdom) and analyzed using a Leica TCS4D true confocal scanning microscope (Milton Keynes, United Kingdom).

\section{Statistical Analyses}

Statistical analysis was performed using unpaired $t$ test on GraphPad Prism software.

\section{Acknowledgements}

We acknowledge Dr. R. Bevan and Dr. G.D.D. Jones for their helpful discussions, and the Food Standards Agency, UK for their financial support.

\section{References}

Amara A, Constans J, Chaugier C, Sebban A, Dubourg L, Peuchant E, Pellegrin JL, Leng B, Conri C, and Geffard M (1995). Autoantibodies to malondialdehyde-modified epitope in connective tissue diseases and vasculitides. Clin Exp Immunol 101:233-238.

Ara J and Ali R (1993). Polynucleotide specificity of antireactive oxygen species (ROS) DNA antibodies. Clin Exp Immunol 94:134-139.

Awada M and Dedon PC (2001). Formation of the 1, $\mathrm{N}^{2}$ glyoxal adduct of deoxyguanosine by phosphoglycolaldehyde, a product of 3 '-deoxyribose oxidation in DNA. Chem Res Toxicol 14:1247-1253.

Cheeseman KH, Beavis A, and Esterbauer H (1988). Hydroxyl-radical-induced iron-catalysed degradation of 2-deoxyribose: Quantitative determination of malondialdehyde. Biochem J 252:649-653.

Cooke MS, Evans MD, Podmore ID, Herbert KE, Mistry N, Mistry P, Hickenbotham PT, Hussieni A, Griffiths HR, and Lunec J (1998). Novel repair action of vitamin $C$ upon in vivo oxidative DNA damage. FEBS Lett 363:363-367.

Cooke MS, Mistry N, Wood C, Herbert KE, and Lunec J (1997). Immunogenicity of DNA damaged by reactive oxygen species: Implications for anti-DNA antibodies in lupus. Free Radic Biol Med 22:151-159.

Cordeiro C and Freire AP (1996). 2-oxoaldehydes, glyoxalase I and oxidative stress. Biochem Soc Trans 24:472S.

Dizdaroglu M (1994). Chemical determination of oxidative DNA damage by gas chromatography-mass spectrometry. Methods Enzymol 234:3-16.

Dizdaroglu M and Bertgold DS (1986). Characterization of free radical-induced base damage in DNA at biologically relevant levels. Anal Biochem 156:182-188.

Everett SM, Singh R, Leuratti C, White KL, Neville P, Greenwood D, Marnett LJ, Schorah CJ, Forman D, Shuker D, and Axon AT (2001). Levels of malondialdehyde-deoxyguanosine in the gastric mucosa: Relationship with lipid peroxidation, ascorbic acid, and Helicobacter pylori. Cancer Epidemiol Biomarkers Prev 10:369-376.

Floyd RA, West MS, Eneff KL, and Schneider JE (1989). Methylene blue plus light mediates 8-hydroxyguanine formation in DNA. Arch Biochem Biophys 273:106-111.

Fogleman AM, Ishaiahu S, Seager J, Hokom M, Child JS, and Edwards PA (1980). Malondialdehyde alteration of low density lipoproteins leads to cholesteryl ester accumulation in 
human monocyte-macrophages. Proc Natl Acad Sci USA 77:2214-2218.

Foiles PG, Akerkar SA, and Chung FL (1989). Application of an immunoassay for cyclic acrolein deoxyguanosine adducts to assess their formation in DNA of Salmonella typhimurium under conditions of mutation induction by acrolein. Carcinogenesis 10:87-90.

Grune T, Michel P, Sitte N, Eggert W, Albrecht-Nebe H, Esterbauer H, and Siems WG (1997). Increased levels of 4-hydroxynonenal modified proteins in plasma of children with autoimmune diseases. Free Radic Biol Med 23:357-360.

Herbert KE, Mistry N, Griffiths HR, and Lunec J (1994). Immunochemical detection of sequence-specific modifications to DNA induced by UV light. Carcinogenesis 15:2517-2521.

Ichihashi K, Osawa T, Toyokuni S, and Uchida K (2001). Endogenous formation of protein adducts with carcinogenic aldehydes: Implications for oxidative stress. J Biol Chem 276:23903-23913.

Kasai H, Iwamoto-Tanaka N, and Fukada S (1998). DNA modifications by the mutagen glyoxal: Adduction to $\mathrm{G}$ and $\mathrm{C}$, deamination of $\mathrm{C}$ and $\mathrm{GC}$ and $\mathrm{GA}$ cross-linking. Carcinogenesis 19:1459-1465.

Kasai $\mathrm{H}$ and Nishimura S (1986). Hydroxylation of guanine in nucleosides and DNA at the C-8 position by heated glucose and oxygen radical-forming agents. Environ Health Perspect 67:111-116.

Klamerth OL (1968). Influence of glyoxal on cell function. Biochim Biophys Acta 155:271-279.

Lo TWC, Selwood T, and Thornalley PJ (1994). The reaction of methylglyoxal with aminoguanidine under physiological conditions and prevention of methylglyoxal binding to plasma proteins. Biochem Pharmacol 48:1865-1870.

Loidl-Stahlhofen A and Spiteller G (1994). $\alpha$-Hydroxyaldehydes, products of lipid peroxidation. Biochim Biophys Acta 1211: 156-160.

Marnett LJ (2000). Oxyradicals and DNA damage. Carcinogenesis 21:361-370.

McBride TJ, Preston BD, and Loeb LA (1991). Mutagenic spectrum resulting from DNA damage by oxygen radicals. Biochemistry 30:207-213.

McBride TJ, Schneider JE, Floyd RA, and Loeb LA (1992). Mutations induced by methylene blue plus white light in singlestranded M13mp2. Proc Natl Acad Sci USA 89:6866-6870.

Mistry N, Evans MD, Griffiths HR, Kasai H, Herbert KE, and Lunec J (1999). Immunochemical detection of glyoxal DNA damage. Free Radic Biol Med 26:1267-1273.

Mlakar A, Batna A, Dudda A, and Spiteller G (1996). Iron (II) ions induced oxidation of ascorbic acid and glucose. Free Radic Biol Med 25:525-539.

Murata-Kamiya N, Kaji H, and Kasai H (1997). Types of mutations induced by glyoxal, a major oxidative DNA-damage product, in Salmonella typhimurium. Mutat Res 377:13-16.

Murata-Kamiya N, Kamiya H, Iwamoto N, and Kasai H (1995). Formation of a mutagen, glyoxal, from DNA treated with oxygen free radicals. Carcinogenesis 16:2251-2253.

Murata-Kamiya N, Kamiya H, Kaji H, and Kasai H (1998). Nucleotide excision repair proteins may be involved in the fixation of glyoxal-induced mutagenesis in Escherichia coli. Biochem Biophys Res Commun 248:412-417.
Nakaya K, Takenaka O, Horinishi H, and Shibata K (1968). Reactions of glyoxal with nucleic acids: Nucleotides and their component bases. Biochim Biophys Acta 161:23-31.

Odani H, Shinzato T, Usami J, Matsumoto Y, Brinkmann Frye E, Baynes JW, and Maeda K (1998). Imidazolium crosslinks derived from reaction of lysine with glyoxal and methylglyoxal are increased in serum proteins of uremic patients: Evidence for increased oxidative stress in uremia. FEBS Lett 427:381-385.

Ravanat J-L, Turesky RJ, Gremaud E, Trudel LJ, and Stadler RH (1995). Determination of 8-oxoguanine in DNA by gas chromatography-mass spectrometry and HPLC-electrochemical detection: Overestimation of the background level of the oxidized base by the gas chromatography-mass spectrometry assay. Chem Res Toxicol 8:1039-1045.

Ruef J, Moser M, Bode C, Kubler W, and Runge MS (2001). 4-hydroxynonenal induces apoptosis, NF-kappaB-activation and formation of 8-isoprostane in vascular smooth muscle cells. Basic Res Cardiol 96:143-150.

Satoh J, Takahashi K, Nakazawa T, Sakata Y, and Toyota T (1999). Current concept of the pathogenesis of autoimmune type 1 diabetes mellitus. Nippon Rinsho 57:528-533.

Sevilla CL, Mahle NH, Eliezer N, Uzieblo A, O'Hara SM, Nokubo M, Miller R, Rouzer CA, and Marnett LJ (1997). Development of monoclonal antibodies to the malondialdehyde-deoxyguanosine adduct, pyrimidopurinone. Chem Res Toxicol 10:172-180.

Shapiro R and Hachmann J (1966). The reaction of guanine derivatives with 1,2-dicarbonyl compounds. Biochemistry 5:2799-2807.

Tanaka N, Tajima S, Ishibashi A, Uchida K, and Shigematsu $\mathrm{T}$ (2001). Immunohistochemical detection of lipid peroxidation products, protein-bound acrolein and 4-hydroxynonenal protein adducts, in actinic elastosis of photodamaged skin. Arch Dermatol Res 293:363-367.

Thornalley PJ (1985). Monosaccharide autoxidation in health and disease. Environ Health Perspect 64:297-307.

Toyokuni S, Tanaka T, Hattori Y, Nishiyama Y, Yoshida A, Uchida K, Hiai H, Ochi H, and Osawa T (1997). Quantitative immunohistochemical determination of 8-hydroxy-2'deoxyguanosine by a monoclonal antibody N45.1: Its application to ferric nitrilotriacetate-induced renal carcinogenesis model. Lab Invest 76:365-374.

Uchida K, Szweda LI, Chae HZ, and Stadtman ER (1993). Immunochemical detection of 4-hydroxynonenal protein adducts in oxidized hepatocytes. Proc Natl Acad Sci USA 90:8742-8746.

Vay D, Parodi M, Rolla R, Mottaran E, Vidali M, Bellomo G, and Albano $E$ (2001). Circulating antibodies recognizing malondialdehyde-modified proteins in healthy subjects. Free Radic Biol Med 30:277-286.

Waszczkowska E, Blaszczyk J, Sysa-Jedrzejowska A, and Robak E (1997). Correlation between serum malonyl dialdehyde concentration and disease activity in patients with systemic lupus erythematosus. Med Sci Monitor 3:831-834.

Wells-Knecht KJ, Zyzak DV, Litchfield JE, Thorpe SR, and Baynes JW (1995). Mechanism of autoxidative glycosylation: Identification of glyoxal and arabinose as intermediates in the autoxidative modification of proteins by glucose. Biochemistry 34:3702-3709. 